\title{
Pengaruh Supervisi Akademik Kepala Sekolah dan Budaya Sekolah Terhadap Mutu Mengajar Guru
}

\author{
Nursidah $^{1}$, Muh Yunus $^{2}$, Elpisah $^{3}$ \\ ${ }^{1}$ STKIP-PI, Makassar, nursydah74@gmail.com \\ ${ }^{2}$ STKIP-PI, Makassar, emyunusjale@gmail.com \\ ${ }^{3}$ STKIP-PI, Makassar, elpisah77.amir@gmail.com
}

\section{DOI}

https://doi.org/10.26740/jupe.v10n1.p38$\underline{44}$

\section{Article history \\ Received \\ 2 December 2021 \\ Revised \\ 12 December 2021 \\ Accepted \\ 15 December 2021}

\section{How to cite}

Nursidah., Yunus, M., \& Elpisah. (2022). Pengaruh Supervisi Akademik Kepala Sekolah dan Budaya Sekolah Terhadap Mutu Mengajar Guru. Jurnal Pendidikan Ekonomi (JUPE), 10(1), 38-44. https://doi.org/10.26740/jupe.v10n1.p38$\underline{44}$

Kata Kunci: Supervisi Akademik Kepala Sekolah, Budaya Sekolah, Pemacah Masalah, Mutu Mengajar Guru Keywords: Principal Academic Supervision, School Culture, Problem Solving, Teacher Teaching Quality

\section{Corresponding author}

Nursidah nursydah74@gmail.com

\begin{abstract}
Abstrak
Tujuan penelitian ini mengetahui 1) Pengaruh supervisi akademik kepala sekolah dan budaya sekolah secara simultan terhadap mutu mengajar guru, 2) Pengaruh supervisi akademik kepala sekolah terhadap mutu mengajar guru, 3) Pengaruh budaya sekolah terhadap mutu mengajar guru di SMAN 6 Wajo. Penelitian ini merupakan penelitian Deskritif Kuantitatif, Populasi seluruh guru SMAN 6 Wajo. Sampel sebanyak 54 orang. Hasil penelitian menunjukkan 1) Terdapat pengaruh supervisi akademik kepala sekolah dan budaya sekolah secara simultan terhadap mutu mengajar guru, dimana indikator supervisi kepala sekolah berada pada kategori baik, sedangkan budaya sekolah dan mutu mengajar guru secara deskriptif berada pada kategori sangat baik, 2) Terdapat pengaruh supervisi akademik kepala sekolah terhadap mutu mengajar guru, dimana supervisi akademik kepala sekolah berpengaruh signifikan terhadap mutu mengajar guru, artinya supervisi akademik kepala sekolah yang semakin baik maka mutu mengajar guru juga meningkat, 3) Terdapat pengaruh budaya sekolah terhadap mutu mengajar guru di SMAN 6 Wajo dimana budaya sekolah berpengaruh signifikan terhadap mutu mengajar guru, artinya budaya sekolah yang yang semakin baik atau kondusif, maka mutu mengajar guru juga meningkat.
\end{abstract}

\begin{abstract}
The purpose of this study was to determine 1) The effect of the principal's academic supervision and school culture simultaneously on the quality of teacher teaching, 2) The influence of the principal's academic supervision on the teaching quality of teachers, 3) The influence of school culture on the teaching quality of teachers at SMAN 6 Wajo. This research is a quantitative descriptive research, the population is all teachers of SMAN 6 Wajo. The sample is 54 people. The results of the study show 1) There is a simultaneous influence of the principal's academic supervision and school culture on the teaching quality of teachers, where the principal's supervision indicators are in the good category, while school culture and teacher teaching quality descriptively are in the very good category, 2) There is an influence The principal's academic supervision on the teaching quality of teachers, where the principal's academic supervision has a significant effect on the teaching quality of teachers, it means that the better the principal's academic supervision, the better the teacher's teaching quality, 3) There is an influence of school culture on the teaching quality of teachers at SMAN 6 Wajo where school culture has a significant effect on the quality of teacher teaching, meaning that the better or conducive school culture, the better the teaching quality of teachers.
\end{abstract}




\section{PENDAHULUAN}

Karena kepala sekolah sebagai pembimbing bagi seluruh guru dan personel di sekolah, maka supervisi akademik kepala sekolah menjadi sangat penting. Selain proses memutar roda pendidikan di sekolah, seorang kepala sekolah juga melakukan supervisi akademik dengan harapan dapat meningkatkan kinerja guru (Djuhartono et al., 2021). Supervisi akademik kepala sekolah sebagai kegiatan bimbingan profesional bagi guru untuk memastikan bahwa mereka dapat melaksanakan kewajiban mengajarnya secara efektif. Indikator utamanya kemampuan guru dalam membina pembelajaran siswa yang aktif, kreatif, berdaya cipta, efektif, efisien, dan menyenangkan (Isbianti1 \& Andriani1, 2021).

Rendahnya kualitas pengajaran guru disebabkan oleh kegagalan kepala sekolah untuk mengatasi kekurangan ini sejak awal. Akibatnya, pembelajaran yang dirancang guru harus memiliki mekanisme dan harus membangun lingkungan yang mendukung proses pembelajaran dengan benar (Sarifudin, 2019). Guru yang dapat melaksanakan tugas dan kewajibannya dengan baik dapat dilihat sebagai indikasi bahwa supervisi akademik dilakukan dengan baik dan tepat oleh kepala sekolah (Aprida et al., 2020).

Pentingnya budaya kerja sekolah sebagai salah satu gagasan yang paling sulit dan krusial dalam pendidikan. Budaya sekolah disebut sebagai "jantung sekolah", yang membuatnya sangat sulit untuk dipahami dan dimodifikasi. Namun, sebagian besar kepala sekolah memiliki pemahaman intuitif bahwa budaya kerja sekolah komponen penting dari keberhasilan sekolah (Kusumaningrum et al., 2019). Kriteria budaya kerja sekolah merupakan kumpulan nilai, keyakinan, asumsi, pemahaman, dan harapan yang dimiliki oleh warga sekolah yang menjadi pedoman perilaku dan solusi atas tantangan yang dihadapi. Kehadiran budaya sekolah dapat memotivasi siswa untuk melaksanakan komitmen dan tugas mereka dan untuk memecahkan kesulitan secara konstan. Kehadiran nilainilai, sikap, keyakinan, dan sebagainya yang dikemas dalam budaya sekolah niscaya akan meningkatkan mutu pendidikan yang diharapkan masyarakat sekolah (Labudasar, 2018).

Pengawasan akademik oleh kepala sekolah Jika ditinjau secara efektif dan akurat, kualitas guru dalam mengajar akan meningkat, demikian pula posisi kepala sekolah sebagai pengemban kendali dalam lembaga pendidikan, yang sangat signifikan dalam mendirikan lembaga pendidikan. Dalam skenario ini, tanggung jawab kepala sekolah dalam meningkatkan mutu pendidikan harus digeser sedemikian rupa sehingga ia dapat mengarahkan dan mendorong para pendidik dan tenaga kependidikan dalam meningkatkan disiplin guru guna menghasilkan pendidikan yang bermutu sesuai dengan prinsip sekolah (Hendra Zeki Y, 2020).

Budaya kerja sekolah terkait dengan supervisi akademik oleh kepala sekolah jika kedua hal ini dilakukan dengan benar, maka kualitas guru dalam melaksanakan proses belajar mengajar akan meningkat. Banyak faktor yang dapat berkontribusi pada budaya kerja sekolah yang negatif, termasuk kecenderungan untuk mempertahankan status quo, menutup diri dari transisi yang terjadi, ceroboh dalam bekerja, canggung, dan tidak memberikan kesempatan kepada orang lain untuk bekerja (Sopaheluwakan, 2020).

Karena pembatasan studi pada supervisi akademik kepala sekolah dan budaya kerja sekolah, mutu mengajaran guru rendah. Penelitian (Ramadhan, 2017) Dampak Supervisi Akademik Pengawas Sekolah dan Supervisi Kepala Sekolah terhadap Kinerja Guru Analisis deskriptif menunjukkan bahwa supervisi akademik pengawas sekolah tidak terlaksana dengan baik dan berada pada kategori rendah, supervisi kepala sekolah terlaksana dengan baik dan berada pada kategori tinggi, dan kinerja guru terlaksana dengan baik dan berada pada kategori tinggi. Hasil analisis inferensial dengan menggunakan regresi linier menunjukkan bahwa: (1) kompetensi supervisi akademik pengawas sekolah berpengaruh signifikan terhadap kinerja guru, (2) supervisi kepala sekolah berpengaruh signifikan terhadap kinerja guru, dan (3) kompetensi supervisi akademik pengawas sekolah dan supervisi kepala sekolah berpengaruh signifikan terhadap kinerja guru.

Pentingnya penelitian ini dalam bidang pendidikan, ditinjau dari supervisi akademik kepala sekolah dan budaya sekolah terhadap mutu mengajar guru di SMAN 6 Wajo. Supervisi akademik kepala sekolah masih jauh dari harapan, supervisi akademik yang diberikan kepala sekolah kepada guru dapat membantu dalam pengembangan keterampilan profesional seperti perencanaan pembelajaran, pelaksanaan proses pembelajaran yang berkualitas, serta penilaian dan evaluasi hasil belajar dalam rangka peningkatan mutu mengajar guru. Selain masalah supervisi akademik, budaya sekolah menjadi faktor yang mempengaruhi mutu mengajar guru, guru dinilai rendah karena kendala yang dihadapi dalam melaksanakan proses pembelajaran, seperti guru tidak merancang desain pembelajaran dan memanfaatkan teknologi pembelajaran semaksimal mungkin. Berkaitan dengan permasalahan di atas, maka tujuan penelitian ini untuk mengetahui: Pengaruh Supervisi Akademik Kepala Sekolah dan Budaya Sekolah Terhadap Mutu Mengajar Guru di SMAN 6 Wajo, Kabupaten Wajo, Sulawesi Selatan. 


\section{METODE}

Jenis penelitian ini merupakan Deskriptif Kuantitatif. Populasi penelitian keseluruhan guru di SMAN 6 Wajo, Kabupaten Wajo, Sulawesi Selatan sebanyak 54 orang, guru PNS sebanyak 35 orang dan guru non PNS sebanyak 19 orang. Sampel penelitian mengunakan teknik (Sampling Jenuh), karena jumlah populasi yang kurang dari 100 orang, maka seluruh populasi dijadikan sampel penelitian sebanyak 54 orang.

Instrumen penelitian yakni variabel bebas $\left(\mathrm{X}^{1}\right)$ supervisi akademik kepala sekolah dan $\left(\mathrm{X}^{2}\right)$ budaya sekolah, (variabel terikat) (Y) mutu mengajar guru. Indikator variabel $\left(\mathrm{X}^{1}\right)$ perencanaan program supervisi akademik, pelaksanaan supervisi, tindak lanjut hasil supervisi. $\left(\mathrm{X}^{2}\right)$ budaya akademik, budaya sosial, budaya demokratif. (Y) kemampuan bidang kognif, kemampuan bidang efektif, kemampuan bidang psikomotorik. Menurut (Arikunto, 2019) Data yang benar akan membawa pada kesimpulan yang sesuai dengan keadaan yang sebenarnya. Benar tidaknya data tergantung pada baik tidaknya instrumen pengumpul data atau pengukur objek dari suatu variabel penelitian.

Teknik pengumpulan data dengan Angket, Dokumentasi. Teknik analisis data mengunakan Analisis Deskriptif, dalam analisis deskriptif terdapat beberapa uji analisis berikut:

1. Analisis statistik deskriptif.

2. Analisis deskriptif inferensial.

$$
\mathrm{P}=\frac{\mathrm{F}}{\mathrm{N}} \times 100 \%
$$

Di mana:

$$
\begin{aligned}
& \mathrm{P} \text { : Angka persentase } \\
& \mathrm{F} \text { : Skor perolehan } \\
& \mathrm{N} \text { : Skor maksimal }
\end{aligned}
$$

Setelah menghitung dengan menggunakan rumus frekuensi di atas, kemudian dimasukkan ke dalam kategori penilaian hasil skor.

\section{HASIL DAN PEMBAHASAN}

\section{Deskripsi Variabel Supervisi Akademik Kepala Sekolah}

Indikator yang di ukur dari supervisi akademik kepala sekolah yaitu perencanan program supervisi, pelaksanaan supervisi dan tindak lanjut hasil supervisi. Untuk melihat gambaran ketiga indikator tersebut, maka dianalisis secara deskriptif dengan menggunakan analisis persentase kemudian dimasukkan ke dalam kategori penilaian. Hasil data dari responden (guru) mengenai supervisi akademk kepala sekolah dapat dilihat pada tabel berikut:
Tabel 1. Deskripsi persentase supervisi Akademik Kepala Sekolah

\begin{tabular}{clcccc}
\hline No & \multicolumn{1}{c}{ Item } & Skor $(\mathbf{P})$ & Skor $(\mathbf{M})$ & $\mathbf{( \% )}$ & Ket \\
\hline 1 & $\begin{array}{l}\text { Perencanaan } \\
\text { program } \\
\text { supervisi }\end{array}$ & 1260 & 1512 & 83,33 & Baik \\
\hline 2 & $\begin{array}{l}\text { Pelaksanaan } \\
\text { supervisi }\end{array}$ & 1874 & 2376 & 87,87 & Baik \\
\hline 3 & $\begin{array}{l}\text { Tindak Lanjut } \\
\text { hasil supervisi }\end{array}$ & 1262 & 1512 & 83,47 & Baik \\
\hline Total skor perolehan & 4396 & 5400 & 245,67 & Baik \\
\hline Rata-rata & 1465 & 1800 & 81,89 & Baik \\
\hline
\end{tabular}

Tabel 1. menunjukkan bahwa supervisi akademik kepala sekolah yang diukur dari indikator program supervisi, pelaksanaan supervisi dan tindak lanjut hasil supervisi secara keseluruhan berada pada kategori baik dengan perolehan skor rata-rata sebesar 1.465 dan persentase sebesar $81,89 \%$ (berada pada interval skor 68 $83 \%$ ). Skor tertinggi ditunjukkan pada indikator tindak lanjut supervisi yaitu sebesar 1.262 dengan frekuensi jawaban responden guru sebesar 194 kali menyatakan bahwa kepala sekolah sering melaksanakan tindak lanjut setelah supervisi. Selanjutnya dari indikator perencanaan program supervisi, berada pula pada kategori baik dengan skor perolehan yaitu sebesar 1.260 dimana frekuensi jawaban reponden guru 181 kali paling dominan menjawab bahwa kepala sekolah sering melakukan perencanaan program sebelum dilaksanakan supervisi.

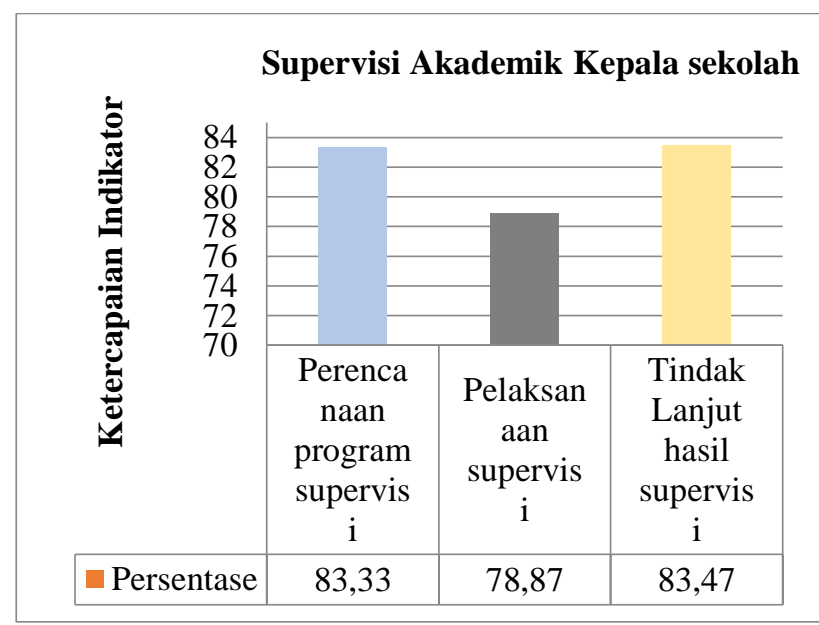

Gambar 1. Presentase Ketercapaian Supervisi Akademik

Gambar 1. dapat dideskripsikan pernyataan responden mengenai supervisi akademik kepala sekolah secara keseluruhan menunjukkan persentase pada kategori baik dari setiap indikator, dimana ketercapaian indikator tertinggi berada pada tindak lanjut supervisi dengan presentase sebesar $83,47 \%$, sedangkan persentase terendah berada pada indikator pelaksanaan supervisi yakni sebesar $78,87 \%$. Berdasarkan grafik tersebut, dapat disimpulkan bahwa tindak lanjut supervisi akademik yang dilaksanakan kepala sekolah menujukkan nilai tertinggi, dimana skor 
jawaban resonden tertinggi berada pada pernyataan kepala sekolah melakukan evaluasi hasil pelaksanaan supervisi akademik dan Kepala sekolah melakukan kegiatan pembinaan sebagai tindak lanjut hasil supervisi.

\section{Deskripsi Variabel Budaya Sekolah}

Varibel budaya sekolah dalam penelitian ini diukur dari tiga indikator yaitu budaya akademik, budaya sosial dan budaya demokratis. Untuk melihat gambaran ketiga indikator tersebut maka dianalisis secara deskriptif dengan menggunakan analisis persentase kemudian dimasukkan ke dalam kategori penilaian. Hasil data dari jawaban responden (guru) mengenai budaya sekolah dapat dilihat pada tabel berikut:

Tabel 2. Deskripsi Persentase Budaya Sekolah

\begin{tabular}{clcccc}
\hline No & \multicolumn{1}{c}{ Item } & Skor $(\mathbf{P})$ & Skor $(\mathbf{M})$ & $\mathbf{( \% )}$ & Ket \\
\hline 1 & $\begin{array}{l}\text { Budaya } \\
\text { academia }\end{array}$ & 1375 & 1512 & 90,94 & Baik \\
\hline 2 & Budaya sosial & 1446 & 1512 & 95,63 & Baik \\
\hline 3 & $\begin{array}{l}\text { Budaya } \\
\text { demokratif }\end{array}$ & 1161 & 1296 & 89,96 & Baik \\
\hline Total skor perolehan & 3982 & 4320 & 276,53 & Baik \\
\hline Rata-rata & 1327 & 1440 & 92,17 & Baik \\
\hline
\end{tabular}

Tabel 4.2 menunjukkan bahwa budaya sekolah yang diukur dari indikator budaya akademik, budaya sosial dan budaya demokratis secara keseluruhan berada pada kategori sangat baik dengan perolehan skor rata-rata sebesar 1.327 dan persentase sebesar $92,17 \%$ (berada pada interval skor $84-100 \%$ ). Skor tertinggi ditunjukkan pada indikator budaya sosial yaitu sebesar 1.446 dengan frekuensi jawaban responden guru sebesar 312 kali menyatakan bahwa pembiasaan sosial selalu diajarkan guru kepada siswa dalam lingkungan sekolah. Selanjutnya dari indikator budaya akademik berada pula pada kategori sangat baik dengan skor perolehan yaitu sebesar 1.375 dimana frekuensi jawaban reponden guru 252 kali menjawab bahwa guru selalu melakukan kebiasaan akademik yang menunjang proses pembelajaran di SMAN 6 Wajo dan 5 orang menjawab guru jarang melakukan budaya akademik, dimana skor terendah dinyatakan bahwa beberapa guru masih jarang membuat RPP secara rutin.

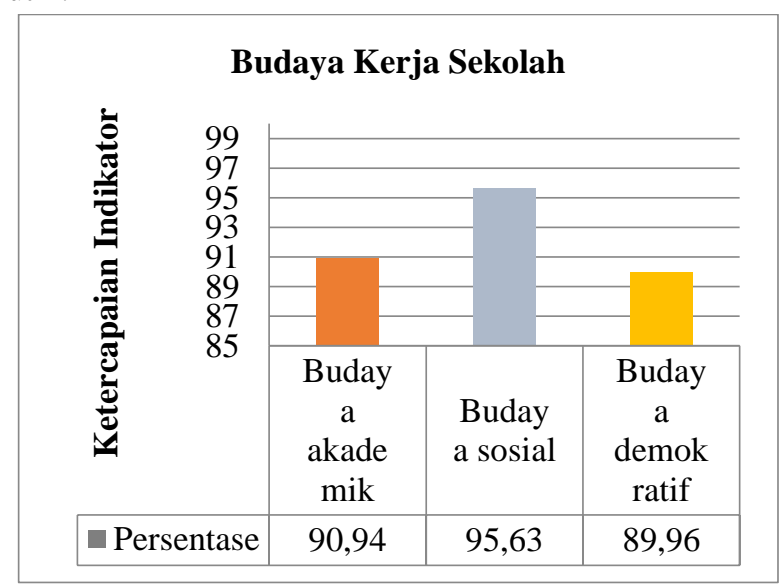

Gambar 2. Presentase Ketercapaian Budaya Sekolah
Gambar 2. dapat dideskripsikan pernyataan responden mengenai budaya sekolah secara keseluruhan menunjukkan persentase sangat baik dari setiap indikator, dimana ketercapaian indikator tertinggi berada pada budaya sosial dengan presentase sebesar 95,63\%, sedangkan persentase terendah berada pada indikator budaya demokratis yakni sebesar $89,96 \%$. Berdasarkan grafik tersebut, dapat disimpulkan bahwa skor tertinggi dari indikator budaya sekolah mengindikasikan beberapa guru di SMAN 6 Wajo telah sangat baik dalam menerapkan nilai-nilai pembiasaan sosial kepada siswa yang melandasi perilaku dan tradisi sekolah, seperti guru membiasakan siswa memelihara kebersihan kelas dengan membuang sampah pada tempatnya.

\section{Deskripsi Variabel Mutu Mengajar Guru}

Mutu mengajar guru dalam penelitian ini diukur dari tiga indikator yaitu kemampuan bidang kognitif, afektif dan psikomotorik. Untuk melihat gambaran ketiga indikator tersebut maka dianalisis secara deskriptif dengan menggunakan analisis persentase kemudian dimasukkan pada kategori penilaian. Hasil data dari jawaban responden (guru) mengenai kemampuan dalam mengajar dapat dilihat pada tabel berikut:

Tabel 3. Deskripsi Persentase Mutu Mengajar Guru

\begin{tabular}{cccccc}
\hline No & \multicolumn{1}{c}{ Item } & Skor $(\mathbf{P})$ & Skor $(\mathbf{M})$ & $\mathbf{( \% )}$ & Ket \\
\hline 1 & $\begin{array}{l}\text { Kemampuan } \\
\text { kognitif }\end{array}$ & 1214 & 1296 & 93,67 & Baik \\
\hline 2 & $\begin{array}{l}\text { Kemampuan } \\
\text { efektif }\end{array}$ & 1458 & 1512 & 96,45 & Baik \\
\hline 3 & $\begin{array}{l}\text { Kemampuan } \\
\text { psikomotorik }\end{array}$ & 1420 & 1512 & 93,91 & Baik \\
\hline Total skor perolehan & 4029 & 4320 & 284,01 & Baik \\
\hline & 1364 & 1440 & 9467 & Baik \\
\hline
\end{tabular}

Tabel 3. menunjukkan bahwa mutu mengajar guru yang diukur dari indikator kemampuan bidang kognitif, afektif dan psikomotorik secara keseluruhan berada pada kategori sangat baik dengan perolehan skor rata-rata sebesar 1.364 dan persentase sebesar 94,67\% (berada pada interval skor $84-100 \%)$. Skor tertinggi ditunjukkan pada indikator kemampuan afektif yaitu sebesar 1.458 dengan frekuensi jawaban responden guru sebesar 326 kali menyatakan bahwa guru selalu menunjukkan kemampuan afektif yang sangat baik dalam mengajar. Selanjutnya dari indikator kemampuan psikomotorik berada pula pada kategori sangat baik dengan skor perolehan yaitu sebesar 1.420 dimana frekuensi jawaban reponden guru 287 kali menjawab bahwa guru selalu menunjukkan kemampuan kognitif yang sangat baik dalam mengajar di kelas. 


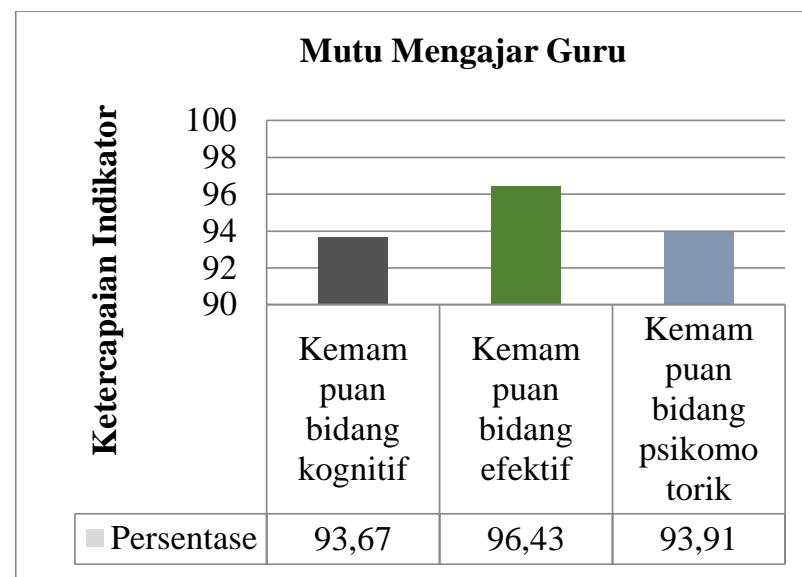

Gambar 3. Presentase Ketercapaian Mutu Mengajar Guru

Gambar 3. dapat dideskripsikan pernyataan responden mengenai mutu mengajar secara keseluruhan menunjukkan persentase sangat baik dari setiap indikator, dimana ketercapaian indikator tertinggi berada pada kemampuan bidang afektif dengan presentase sebesar $96,43 \%$, sedangkan persentase terendah berada pada indikator kemampuan bidang psikomotorik yakni sebesar $93,91 \%$. Berdasarkan grafik tersebut, dapat disimpulkan bahwa mutu mengajar guru tertinggi berada pada kemampuan guru dari aspek afektif, sehingga mengindikasikan sikap guru selama proses pembelajaran sangat baik, seperti guru telah memberikan kesempatan pada siswa untuk menanyakan materi yang belum jelas.

Pengaruh Supervisi Akademik Kepala Sekolah dan Budaya Sekolah Terhadap Mutu Mengajar Guru

Berdasarkan hasil penelitian yang telah dicapai, maka diperoleh bahwa ada pengaruh supervisi akademik kepala sekolah dan budaya sekolah terhadap mutu mengajar guru di SMAN 6 Wajo. Hal tersebut dapat dilihat dari hasil perhitungan dengan SPSS menunjukkan bahwa koefisien regresi untuk variabel supevisi akademik kepala sekolah (X1) sebesar 0,118, budaya sekolah (X2) sebesar 0,083, dan juga menghasilkan nilai konstanta sebesar 60,250., sehingga persamaan regresi linear berganda adalah: Ý = $60,250+0,118 \mathrm{X} 1+0,083 \mathrm{X} 2+$ e. Konstanta sebesar 60,250 menyatakan bahwa jika tidak ada peningkatan supevisi akademik kepala sekolah (X1) dan budaya sekolah (X2), secara matematika, X1, dan X2 adalah 0 , maka mutu mengajar guru tetap sebesar 60,250 unit skor. Dengan melihat besarnya koefisien regresi bahwa variabel supervisi akademik kepala sekolah (X1) 0,118 atau sama dengan $11,8 \%$, sedangkan koefisien regresi variabel budaya sekolah (X2) sebesar 0,083 atau sama dengan $8,3 \%$, Hal ini berarti kecenderungan proyeksi perubahan variabel X1 lebih besar daripada X2 terhadap Y. Hal ini sesuai dengan (Purbasar, 2015) Supervisi akademik diartikan sebagai pelaksanaan supervisi yang berkaitan dengan upaya supervisor dalam membantu guru dalam mengembangkan kemampuannya untuk mengontrol proses pembelajaran guna mencapai tujuan pembelajaran.

(Siregar, 2020) Supervisi akademik dalam bentuk pembinaan dan bantuan yang diberikan kepada guru/pendidik dalam rangka meningkatkan lingkungan belajar mengajar Akibatnya, guru terus meningkatkan cara mereka mengajar mata pelajaran dan meningkatkan kemanjuran pekerjaan mereka, yang meningkatkan kualitas pendidikan di sekolah. Sedangkan menurut (Manaf \& Omar, 2018) Budaya sekolah terbentuk melalui proses kegiatan yang mengedepankan implementasi kurikulum pembelajaran di sekolah, menjadikan budaya sekolah memiliki dampak yang signifikan terhadap aktivitas manusia dan hubungan dalam organisasi sekolah, budaya sekolah yang mapan, dan memberikan solusi yang sudah ada, sudah ada dalam budaya sekolah. , membangun berbagai hubungan dan kerjasama serta resolusi konflik dalam organisasi sekolah.

\section{Pengaruh Supervisi Akademik Kepala Sekolah Terhadap Mutu Mengajar Guru}

Berdasarkan hasil penelitian telah membuktikan adanya pengaruh signifikan supervisi akademik kepala sekolah terhadap mutu mengajar guru di SMAN 6 Wajo. Hal tersebut dapat dilihat bahwa supervisi akademik kepala sekolah $\left(\mathrm{X}_{1}\right)$ secara parsial berhubungan erat (signifikan) terhadap mutu mengajar guru di SMA 6 wajo. Berdasarkan hasil analisis regresi diperoleh nilai $\mathrm{t}_{\text {-hitung }}=$ 2,172, sedangkan $t$-tabel sebesar 1,675, sehingga disimpulkan bahwa $t$-hitung $>t$-tabel, berarti supervisi akademik berpengaruh signifikan terhadap mutu mengajar guru. Cara kedua, membandingkan hasil signifikan yaitu 0,035 , berarti lebih kecil dari 0,05, sehingga dapat pula disimpulkan bahwa supervisi akademik berpengaruh signifikan terhadap mutu mengajar guru. Hasil tersebut (Anggada, 2021) Sebelum memulai kegiatan supervisi akademik, kepala sekolah harus membuat rencana berupa rencana kompetensi kepala sekolah. Bagi seorang kepala sekolah, relevansi sebuah rencana menjadi acuan dalam menjalankan proses pengelolaan lembaga pendidikan. Perencanaan yang matang dapat menjadi motor penggerak bagi sekolah untuk mendorong proses pengelolaan lembaga pendidikan sesuai dengan rencana yang telah disusun dan tujuan yang harus dicapai.

\section{Pengaruh Budaya Sekolah Terhadap Mutu Mengajar Guru}

Berdasarkan hasil penelitian pada variabel budaya sekolah secara parsial berhubungan erat (signifikan) terhadap mutu mengajar guru di SMAN 6 Wajo. Berdasarkan hasil analisis regresi diperoleh Nilai t-hitung= 2,510, sedangkan $t_{\text {-tabel }}$ sebesar 1,67, sehingga disimpulkan bahwa $t_{\text {-hitung }}>t_{\text {-tabel, }}$, berarti budaya sekolah berpengaruh signifikan terhadap mutu mengajar guru. Cara kedua, membandingkan hasil signifikan yaitu 0,015 , berarti lebih 
kecil dari 0,05, sehingga dapat pula disimpulkan bahwa budaya sekolah berpengaruh signifikan terhadap mutu mengajar guru. Hal tersebut (Kusumaningrum et al., 2019) mengatakan bahwa budaya positif ketika guru mengomunikasikan visi bersama dan siswa mencapainya, atau bahwa mereka perlu bekerja pada budaya sekolah ketika beberapa guru pergi atau tingkat disiplin di antara siswa meningkat. Namun, kepala sekolah, seperti banyak pemimpin organisasi, mungkin berkecil hati ketika mencoba menjelaskan aspek-aspek yang berkontribusi pada budaya positif. Sulit untuk didefinisikan, dan menguraikan konstituennya bisa jadi sulit. Menurut (Sopiah \& Herman, 2018) mengatakan bahwa budaya kerja menggambarkan bagaimana dan apa yang karyawan lakukan di tempat kerja. Tugas guru adalah memberikan layanan belajar kepada siswa. Kompetensi guru berpengaruh terhadap prestasi belajar siswa yang berujung pada peningkatan kualitas pendidikan. Guru adalah pendidik yang tanggung jawab utamanya adalah melaksanakan kegiatan belajar mengajar.

\section{SIMPULAN}

Dari hasil penelitian dan pembahasan dapat ditarik kesimpulan di SMAN 6 Wajo, supervisi akademik kepala sekolah dan budaya sekolah berpengaruh secara simultan terhadap kualitas mengajar guru, dengan indikator supervisi kepala sekolah dalam kategori baik dan budaya sekolah dan kualitas mengajar guru secara deskriptif dalam kategori sangat baik. Supervisi akademik kepala sekolah berpengaruh signifikan terhadap kualitas mengajar guru di SMAN 6 Wajo, dimana supervisi akademik kepala sekolah berpengaruh signifikan terhadap kualitas mengajar guru, artinya semakin baik supervisi akademik kepala sekolah maka semakin baik pula kualitas pengajaran guru. Di SMAN 6 Wajo, budaya sekolah berpengaruh signifikan terhadap kualitas guru mengajar, artinya semakin baik atau semakin kondusif budaya sekolah maka semakin baik pula kualitas pengajaran guru.

\section{UCAPAN TERIMAKASIH}

Ucapakan terima kasih kepada Dr. Muh. Yunus, M.Pd dan Dr Elpisah, S.E, M.Pd selaku pembimbing yang memberikan kontribusi selama penyususun tesis ini, Ucapan terima kasih untuk SMAN 6 Wajo yang sudah memberikan izin kepada peneliti untuk melaksanakan penelitian ini.

\section{DAFTAR PUSTAKA}

Anggada, R. (2021). SEKOLAH DALAM
MENINGKATKAN KINERJA GURU PADA
MASA PANDEMI COVID-19 DI SMA NEGERI 1
SIDOARJO. Jurnal Inspirasi Manajemen
Pendidikan, 9(4), 846-858.

Aprida, Y., Fitria, H., \& Nurkhalis, N. (2020). Pengaruh Supervisi Kepala Sekolah dan Motivasi Kerja Guru Terhadap Kinerja Guru. Journal of Education Research, 1(2), 160-164. https://doi.org/10.37985/joe.v1i2.16

Arikunto. (2019). Prosedur Penelitian: suatu pendekatan praktek. Jakarta: Rineka Cipta.

Djuhartono, T., Ulfiah, U., Hanafiah, H., \& Rostini, D. (2021). Supervisi Akademik Kepala Sekolah Dalam Meningkatkan Kinerja Guru Kejuruan. Research and Development Journal of Education, 7(1), 101. https://doi.org/10.30998/rdje.v7i1.9147

Hendra Zeki Y, Y. (2020). Peran Kepala Sekolah dalam Meningkatkan Mutu Pendidikan Di SDN 18/III Tarutung Kabupaten Kerinci. Jurnal Gantala Pendidikan Dasar, 5(2), 168-182.

Isbianti1, P., \& Andriani1, D. E. (2021). Jurnal Manajemen Pendidikan Pelaksanaan Supervisi Akademik oleh Kepala Sekolah Menengah Pertama Negeri di Klaten Jawa Tengah Academic Supervision Practices of Junior High School Principals in Klaten, Central Java. Jurnal Manajemen Pendidikan, 3(1), 75-85.

Kusumaningrum, D. E., Sumarsono, R. B., \& Gunawan, I. (2019). Budaya Sekolah dan Etika Profesi : Pengukuran Pemberdayaan Sumber Daya Manusia Sekolah dengan Pendekatan Soft System Methodology. JAMP: Jurnal Adminitrasi Dan Manajemen Pendidikan, 2(3), 90-97.

Labudasar, E. (2018). PERAN BUDAYA SEKOLAH DALAM MENINGKATKAN KARAKTER SISWA SEKOLAH DASAR Erna Labudasari, Eliya Rochmah. Jurnal Pendidikan Dasar PerKhasa, 4(01), 299-310.

Manaf, A., \& Omar, C. M. Z. C. (2018). NILAI BUDAYA SEKOLAH DALAM PELAKSANAAN KURIKULUM PENDIDIKAN DI SMK BEKASI. Tarbawi: Jurnal Keilmuan Manajemen Pendidikan, 4(01),

101. https://doi.org/10.32678/tarbawi.v4i01.1951

Purbasar, M. (2015). Pengaruh Supervisi Akademik Terhadap Kinerja Mengajar Guru Di Sekolah Dasar. Journal of Elementary Education, 4(1), 46-52.

Ramadhan, A. (2017). Pengaruh Pelaksanaan Supervisi Akademik Pengawas Sekolah Dan Supervisi Kepala Sekolah Terhadap Kinerja Guru SMK Negeri Di Kabupaten Majene. Journal of Educational Science and Technology (EST), 3(2), 136. https://doi.org/10.26858/est.v3i2.3579

Sarifudin, A. (2019). Peningkatan Kinerja Guru Dalam Impelementasi Penilaian Sistem SKS Melalui Supervisi Akademik Pengawas Sekolah. Jurnal Pendidikan Islam, 08(02), 417-434.

Siregar, D. (2020). PENINGKATAN MUTU PEMBELAJARAN DENGAN PENDEKATAN PAKEM GURU KELAS V DAN VI MELALUI SUPERVISI KELAS DI SDN. 118267 AEK RASO T.A. 2018/2019. Bahasa Indonesia Prima Journal, 2(2), 74-81.

Sopaheluwakan, N. (2020). Hubungan Antara Kepemimpinan Kepala Sekolah Dan Budaya Kerja 
Dengan Kinerja Guru Sma Negeri 1 Seram Barat Kabupaten Seram Bagian Barat. Jurnal Manajemen
Pendidikan,
$9(2)$
102-118.

https://doi.org/10.33541/jmp.v9i2.3015

Sopiah, S., \& Herman, M. (2018). Pengaruh Kemampuan

Manajerial Kepala Sekolah dan Budaya Kerja Guru Terhadap Kompetensi Guru. Journal Education Management Dan Administration Review, 2(2), 2-8. 